\title{
Customization Of Instant Feedback For Integrated Assignments: A Case Study
}

Steven J. Adams, (Email: sjadams@csuchico.edu), California State University, Chico

Sally L. Adams, California State University, Chico

LeRoy J. Pryor, California State University, Chico

\begin{abstract}
This paper describes a project which developed 26 sophisticated spreadsheet templates designed to give students instant feedback on integrated case assignments in introductory accounting courses. The approach, however, can be used in any course with a quantitative component and can be used by any instructor with intermediate spreadsheet skills. Students were required to complete unique, pre-formatted templates programmed to provide feedback immediately following the completion of a cell formula. Anonymous questionnaires were completed by students at semester's end and faculty met to discuss their observations. Students reported that they liked the templates and spent more time on their homework because of the instant feedback, but were undecided as to whether completing the computer-graded templates helped them on exams. The faculty observed students to be more prepared to discuss the cases when the instant feedback templates were used.
\end{abstract}

\section{INTRODUCTION}

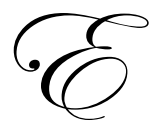

ducation research has shown that students are prone to incorrectly assess the objective state of their knowledge (Glenberg et al., 1984). The predominant direction of students' self-assessment is to overstate subject mastery. These findings are pervasive and apply to both motor skills as well as higher order cognitive learning. The gap between subjective self-assessment and objective states of knowledge is termed by Glenberg et al. as the "illusion of knowing." Introductory accounting instructors often observe that students are puzzled by poor performance on exams for which students believed they were well prepared. Familiarity with words in an exam question or homework question appears to give a student the illusion of knowing, even though the question may be asking for an analytical or relational response more complex than a simple definition.

A study by Homa and Cultice (1984) which tested the effects of feedback in a learning situation is representative of feedback research. The test variable was the accuracy rate of categorizing geometric patterns, distorted by a statistical decision rule, on eight successive learning trials. One group of subjects was given no feedback at the end of each trial. The other group was given immediate corrective feedback at the end of each trial. Performance in the first trial was, as expected, about the same for the feedback and non-feedback groups. On successive learning trials, performance dramatically accelerated for the feedback group. In contrast, the no-feedback group exhibited no improvement in accuracy of categorizing the patterns. The performance of the no-feedback group stayed at the initial levels. Feedback was identified as the treatment effect causing a marked improvement in learning performance.

The critical importance of timely feedback to effective learning, particularly when tackling a new subject, is widely recognized. In their classic article, Chickering and Gamson (1987) list timely feedback as one of the seven principles of good practice in higher education. They state, "No feedback can occur without assessment. But assessment without timely feedback contributes little to learning" (p. 8). Chickering and Ehrmann (1996) discuss how technology can improve the timeliness of feedback. One key component of a frequently cited model of learning, referred to as "The Wheel of Learning," developed by Kolb (1984), is timely feedback, which he considered necessary before further learning can take place. 
The importance of prompt feedback has been explored in the accounting literature as well. For example, Stuart (2004) conducted an experiment involving analytical review tasks in an auditing class. The large class was divided into three groups: a control group which received no training, practice, or feedback; a group which received all three; and a third group which received all but the feedback treatment. The group of students who received the immediate feedback outperformed the other two groups on a test of analytical review procedures.

Many introductory accounting instructors understand the problem of providing timely feedback. The material to be learned is challenging, and students make frequent errors when working problems. Collecting homework, grading it, and returning it at the next class period is not very effective, perhaps because the feedback delay is too long to reinforce learning. Covering homework in detail during class also consumes significant time. One option is to make the solutions to homework available to the students in advance. For students who use the solutions correctly as feedback after working the problem, this is a workable alternative. Many students, however, will simply look at the solution as they solve the problems. The result is that these students will likely believe that they have mastered the concepts when in fact they have learned little. There are many multiple choice computerized questions that provide instant feedback, but such an approach is not likely to not develop higher-level skills in a given subject matter as effectively as completing solutions to problems and cases requiring more comprehensive development.

Research in education suggests that assignments should provide students with prompt feedback (Chickering and Gamson, 1987). Additionally the feedback should be designed so that one unsolvable step in a complex problem will not prevent the student from learning by completing subsequent steps. In other words, a difficulty with one step of a problem should not prevent the student from attempting the rest of the integrative problem.

The purpose of this paper is to report on a project to embed unique computerized, instant-feedback templates into introductory accounting courses. The nature of the courses and the templates developed are first described. Results of surveys administered to students, as well as faculty debriefings are next presented. The paper concludes with a discussion of the benefits and disadvantages of using the templates.

\section{COURSE PEDAGOGY}

Each of the two semester-long introductory courses uses a case pedagogy that extends and builds throughout the semester, termed a serial case. The first semester case presents the student with the context of a proprietorship that evolves into a partnership and then a corporation. As the complexity of the business increases, various accounting issues are introduced that are relevant to the specific growth stage of the enterprise, such as inventory turnover ratios and average collection period of receivables. Each week of the semester challenges the student to consider and learn additional accounting topics relevant to the serial case.

The second semester serial case focuses on a manufacturing business. Similar to the first course, the syllabus calls for a weekly analysis of data concerning the manufacturing of the company's products. Manufacturing costs, work in process valuation, just-in-time costing, activity based costing and return on investment are some of the topics introduced as the student studies the company data over several fictional years.

The homework assignments are a blend of data analysis and essay questions. We provide a formatted spreadsheet template for many of these case assignments. Exhibit 1 contains a sample of one of the templates. Our goal in providing the templates is to have the students focus their time on conceptual aspects of the course material, rather than get bogged down with formatting numerous spreadsheets. Accordingly, the student is required to construct cell formulae within the provided templates to compute each required value for the analyses. 


\section{The Templates}

Students complete 13 Excel templates for homework each semester. Excel is readily available at a low cost to students and is generally installed in campus labs. In addition to having the necessary mathematical functions, Excel also has extensive formatting options, and readily available help menus. Because this software program is widely used in business, spreadsheet knowledge is considered a necessary skill for our business graduates. Our template approach improves the acquisition of this requisite skill.

Although many accounting textbooks have required students to complete excel templates for some time, we find the traditional templates to be unsatisfactory in the following ways:

- There is generally no consistency in format and presentation from one template to another.

- $\quad$ Each student is provided the same problem data so the correct numerical response is the same for each student.

- The feedback process is usually performed after the entire assignment is completed vs. on an "as you go" basis. When the feedback is instantaneous, students are unable to go back and correct an incorrect response.

- $\quad$ The feedback process requires that problems must be relatively simple with each answer independent of subsequent answers.

Our templates are designed to correct each of the previous issues as further discussed below.

\section{Customizing The Template Layout}

A sample template file is presented as Exhibit 1. To address issue 1 above, the template appearance is customized through the use of background colors in cells, so that a student can quickly determine the purpose of each cell. For example, cells with a purple background denote instructions. Each student's unique numerical assumptions have a green background. Yellow cells designate information to be completed by the student. Light yellow cells reflect intermediate steps that are not instantly graded. Additionally, the light yellow color is used for essay responses. The blue area is used to provide feedback. For more challenging requirements, comment boxes can be added to a cell to give hints or suggestions. Comment boxes display as red triangles in the upper right hand area of the cell. A comment for cell I25 is shown in Exhibit 1. By making the color code of each template similar, the goal is to make students immediately feel comfortable with the format of later assignments so they can attack the problem with less start-up time.

\section{Creating A Unique Template For Each Individual Student}

As mentioned in issue 2 above, traditional templates require students to work identical problems with only one correct numerical answer. The templates give each student unique problem data which by its very nature results in a different numerical solution for each student. Since each answer is dependent solely on that individual's unique data, copying another's numerical answer is ineffective and most assuredly incorrect. This provides each student with an added incentive to complete his own assignment.

\section{The Feedback Process}

The feedback process provides students and instructors with "grading" information. The feedback portion of the template has a blue background and informs the student whether the answer in a specific cell is correct or incorrect, as well as the number of points the response has earned, usually 0,1 , or 2 . Unlike traditional spreadsheets, the student can see the accuracy of his input immediately after entering it rather than having to wait until additional problem requirements are completed. A "correct" response encourages the student while an "incorrect" answer can immediately be identified and corrected. The template sums the points as they are earned and the total is normalized producing a score in which 10 points represents the highest grade attainable. In Exhibit 1, the student's total points are 25 (see cell O37), which normalizes to 9.62. Twenty-six points would have produced a score of 10. 
One additional benefit is that the grading is completed right on the student's template using the Excel program in close proximity to the problem data and student input. No internet connection is required for the grading process and the grading result is not displayed on a different screen.

\section{Creating Complex Templates}

Most traditional templates consist of short questions whose answers do not build on previous answers. If longer, more complex problems are given, a numerical error earlier in the problem results in all subsequent answers being scored as incorrect. This is especially frustrating to the student and oftentimes causes a student to quit attempting to solve the problem knowing that all subsequent answers will be incorrect. Our templates, however, consider the student's previous answer in the grading of the subsequent question. For example, the student entry in cell F30 is incorrect and therefore receives 0 points (as shown in cell O34). Cell F32 is dependent on the student input in cell F30. The "correct" shown in cell N35 designates that the student entered the right formula in cell F32. The box around the amount $\$ 43,480$ shown in cell M35 informs the student that the numerical amount is incorrect. The student is not penalized for the incorrect numerical amount if the logic expressed in the student's input formula for that cell is correct. This encourages the student to complete the entire assignment to gain additional points.

In the description of the feedback process, note the emphasis is on the student entering the correct formula vs. the correct numerical amount. This is a critical way in which the templates are differentiated from other templates used today. Because our spreadsheets emphasize the input of formulas, instructors can take the templates one step further showing how easy it is to do "what if" analyses.

\section{Template Mechanics}

Each student downloads his template from a website. Before viewing the template, a pop-up macro asks the student for name and four digit unique identifying number. This macro then posts this information in cells A1 and A2 on the template. Each template uses V lookup tables to determine the unique data placed in the green cells based on the student's four digit identifying number. All cells on the worksheet are then "locked" with their formulas "hidden" except for the yellow cells to be completed by the students.

The grading of the template was accomplished by creating a solution spreadsheet for that template. That spreadsheet was "hidden" in the workbook so that the students could not see an additional spreadsheet existed. The workbook was then "locked." The student's spreadsheet was then compared to the solution spreadsheet to determine its accuracy. For each cell designated to provide feedback, the student's formula for that cell is compared with the "solution" formula for that cell. This comparison is done by using multiple "IF" statements. If the formulas are equal, the text "correct" is displayed and points are given for the "correct" response. If the formulas for the student's worksheet and the "solution" are the same but the numerical values are not identical, the cell is still be graded as "correct" but a box is displayed (using the conditional formatting feature of Excel) around the numerical answer in the grading portion of the template.

\section{QUESTIONNAIRE RESULTS}

It is not the purpose of this paper to report the results of an experiment in the educational effectiveness of using instant feedback templates. We did, however, solicit the students' view of the template approach by administering a questionnaire each semester for one year to 303 financial accounting students and 284 managerial accounting students. The questionnaire, presented as Exhibit II, used a 5-point scale. A "strongly agree" response was given a 5, an "agree" response was a 4, a "neutral" response was a 3, a "disagree" response was a 2, and a "strongly disagree" response was assigned a point value of 1 . The questionnaires were administered in class at the end of the semester. Responses were anonymous with no names attached to the response and students were assured that there was no way to match the questionnaire with an individual student completing it. We also held a debriefing session with all instructors at the end of the semester at which instructor observations were recorded. 
Exhibit II

Student Questionnaire

\begin{tabular}{|c|c|c|c|c|}
\hline \multicolumn{2}{|r|}{ Student Questionnaire } & \multicolumn{3}{|c|}{ Results } \\
\hline \# & $\begin{array}{l}5=\text { Strongly Agree, } 4=\text { Agree, } 3=\text { Neutral, } 2=\text { Disagree, } \\
1 \text { = Strongly Disagree }\end{array}$ & $\begin{array}{c}\text { Financial } \\
\text { Accounting }\end{array}$ & $\begin{array}{l}\text { Managerial } \\
\text { Accounting }\end{array}$ & $\begin{array}{l}\text { Weighted } \\
\text { Average }\end{array}$ \\
\hline 1 & $\begin{array}{l}\text { The time I spent on homework decreased as a result of the computer- } \\
\text { graded case templates. }\end{array}$ & 3.23 & 3.48 & 3.35 \\
\hline 2 & I felt the instant grading feature of the template was very helpful. & 4.39 & 4.43 & 4.41 \\
\hline 3 & I found the color scheme for the computer-graded templates to be helpful. & 4.06 & 4.05 & 4.06 \\
\hline 4 & $\begin{array}{l}\text { My learning increased as a result of using the computer-graded case } \\
\text { templates. }\end{array}$ & 3.36 & 3.46 & 3.41 \\
\hline 5 & The computer-graded case templates were not helpful in studying for tests. & 2.86 & 2.65 & 2.76 \\
\hline 6 & My excel skills improved as a result of the computer-graded templates. & 3.80 & 3.51 & 3.66 \\
\hline 7 & $\begin{array}{l}\text { I found the computer-graded feature of the template to be frustrating at } \\
\text { times. }\end{array}$ & 3.25 & 3.01 & 3.14 \\
\hline 8 & I prefer doing the homework on templates I create myself. & 2.24 & 1.91 & 2.08 \\
\hline 9 & I think the computer-graded templates were generally too easy. & 2.14 & 2.12 & 2.13 \\
\hline 10 & I think the computer-graded templates made the homework more fun. & 3.43 & 3.28 & 3.36 \\
\hline 11 & Doing the computer-graded case templates helped me do better on exams & 3.03 & 3.13 & 3.08 \\
\hline 12 & $\begin{array}{l}\text { I found myself trying to find the correct answer if the template said my } \\
\text { answer was incorrect. }\end{array}$ & 4.29 & 4.31 & 4.30 \\
\hline 13 & $\begin{array}{l}\text { I like the fact that I can see when the equation is correct but the numerical } \\
\text { value is wrong. }\end{array}$ & 4.03 & 4.14 & 4.08 \\
\hline 14 & $\begin{array}{l}\text { I like the fact that I get points when the equation is correct but the } \\
\text { numerical value is wrong. }\end{array}$ & 3.85 & 4.03 & 3.94 \\
\hline 15 & I think the computer-graded templates should be required for this class. & 3.50 & 3.62 & 3.56 \\
\hline 16 & $\begin{array}{l}\text { I often just typed in formulas until it was "correct" without paying } \\
\text { attention to what I was doing. }\end{array}$ & 2.86 & 2.79 & 2.83 \\
\hline 17 & Completing the computer-graded templates helped me do better on exams & 3.08 & 3.20 & 3.14 \\
\hline 18 & $\begin{array}{l}\text { The computer-graded templates did not prepare me for the equations and } \\
\text { reasoning needed on the exams }\end{array}$ & 2.96 & 2.98 & 2.97 \\
\hline 19 & Compared to other courses, I spent less time on this course. & 2.00 & 1.88 & 1.94 \\
\hline 20 & I have a more favorable view of accounting after taking this class. & 3.22 & 2.83 & 3.03 \\
\hline 21 & $\begin{array}{l}\text { For cases that did not have computer-graded templates, I often just } \\
\text { completed the requirements not really trying to find the correct answer. }\end{array}$ & 2.69 & 3.06 & 2.87 \\
\hline 22 & $\begin{array}{l}\text { If the computer-graded template said the answer was wrong, I generally } \\
\text { did not try to find out why. }\end{array}$ & 1.78 & 1.85 & 1.82 \\
\hline 23 & I enjoyed this class more than I thought I would. & 3.21 & 2.87 & 3.04 \\
\hline 24 & $\begin{array}{l}\text { I spent more time trying to find the correct answer on cases that used } \\
\text { computer-graded templates, then those than didn't. }\end{array}$ & 3.72 & 3.59 & 3.65 \\
\hline 25 & $\begin{array}{l}\text { I believe that using computers is an effective way to learn about } \\
\text { accounting and business. }\end{array}$ & 4.18 & 4.17 & 4.17 \\
\hline
\end{tabular}

\section{Increased Student Time On Task}

No matter how effective course materials are in aiding learning, disciplines like accounting require that students commit significant time to their studies in order to master the material. Both anecdotal comments from students, as well as empirical data collected on the student surveys (see Table 1), show that the computer-graded templates encourage students to spend more time on homework assignments. Increased time on task is generally acknowledged to enhance student learning (Chickering \& Gamson, 1987).

Table 1 lists the questions that are related to the time-on-task issue. The significance levels in Table 1 indicate whether the observed mean response is different from a neutral or 3 average response. The results for question 1 indicate a weak response of a decrease in homework time, although responses for both courses are closer to neutral than to agreement with the statement. Since students had to create some excel case templates from scratch 
earlier in the course, this response may reflect their feeling that computer-graded templates allowed them to spend less time on template preparation and more time on problem solution and interpretation. In any case, responses to the remaining five questions are consistent with the notion that the computer-graded templates increase time on important learning tasks, namely the creation of formulas that correctly reflect the required analyses. Responses to two questions, "I found myself trying to find the correct answer if the template said my answer was incorrect" (question 12) and question 24 , its negatively worded counterpart, are interesting. The answers to question 12 are significantly different from a neutral response at the .05 level of significance for both courses. The answers to question 24 are significant at the .10 level for both courses. Students disagreed with Question 9, "I think the computer-graded templates are too easy," at the .15 level for both courses. Students in the managerial course also disagreed with question 19, "Compared to other courses taken, I spent less time on this course," at the .15 level.

TABLE 1

Time On Task

\begin{tabular}{|c|l|c|c|c|}
\hline \multicolumn{1}{|c|}{ Student Questionnaire } & \multicolumn{3}{c|}{ Results } \\
\hline$\#$ & $\begin{array}{l}\mathbf{5}=\text { Strongly Agree, 4 = Agree, 3 = Neutral, 2 = Disagree, } \\
\mathbf{1}=\text { Strongly Disagree }\end{array}$ & $\begin{array}{c}\text { Financial } \\
\text { Accounting }\end{array}$ & $\begin{array}{c}\text { Managerial } \\
\text { Accounting }\end{array}$ & $\begin{array}{c}\text { Weighted } \\
\text { Average }\end{array}$ \\
\hline 1 & $\begin{array}{l}\text { The time I spent on homework decreased as a result of the computer- } \\
\text { graded case templates. }\end{array}$ & 3.23 & 3.48 & 3.35 \\
\hline 9 & I think the computer-graded templates were generally too easy. & $2.14 *$ & $2.12 *$ & 2.13 \\
\hline 12 & $\begin{array}{l}\text { I found myself trying to find the correct answer if the template said my } \\
\text { answer was incorrect. }\end{array}$ & $4.29 * * *$ & $4.31 * * *$ & 4.30 \\
\hline 19 & Compared to other courses, I spent less time on this course than others. & 2.00 & $1.88^{*}$ & 1.94 \\
\hline 21 & $\begin{array}{l}\text { For cases that did not have computer-graded templates, I often just } \\
\text { completed the requirements not really trying to find the correct answer. }\end{array}$ & 2.69 & 3.06 & 2.87 \\
\hline 24 & $\begin{array}{l}\text { I spent more time trying to find the correct answer on cases that used the } \\
\text { computer-graded templates, then those than didn't. }\end{array}$ & $3.72 * *$ & $3.59 * *$ \\
\hline & $* * *$ Significant at the .05 level; ** Significant at the .10 level; * Significant at the .15 level & 3.65 \\
\hline
\end{tabular}

\section{Increased Student Perceived Learning}

The quality in terms of homework sections attempted with good effort and correctness of assignments increased noticeably. All instructors reported improved homework performance on the computer-graded templates as compared to the non-computer-graded case assignments. Instructors also noted that performance on test questions related to these templates also improved, although students did not share that opinion.

Student responses to perceived learning questions are presented as Table 2. Students report that the feedback provided by the templates does cause them to try to find out why an answer is incorrect. To negatively stated question 22, "If computer-graded case templates said the answer was wrong, I generally did not try to find out why," the students disagreed at the .10 significance level in both courses. Thus, the students indicate that it is the feedback feature that motivates them to get a better score by trying to find out why their answer was incorrect. Students also believe, at the .10 significance level in both courses, that "using computers is an effective way to learn about accounting and business" (almost all of the computer work in the classes involved using Excel to solve assignments). Somewhat disappointingly, students did not believe that the computer-graded templates helped them score better on exams (questions 18 and 11). Students were somewhat more positive that "my learning increased as a result of using the computer-graded case templates" (question 4), with responses of 3.36 and 3.46 for the two courses, these results are not significant at the .15 level. 
TABLE 2

Student Perceived Learning

\begin{tabular}{|c|c|c|c|c|}
\hline \multicolumn{2}{|r|}{ Student Questionnaire } & \multicolumn{3}{|c|}{ Results } \\
\hline \# & $\begin{array}{l}5=\text { Strongly Agree, } 4=\text { Agree, } 3=\text { Neutral, } 2 \text { = Disagree } \\
1=\text { Strongly Disagree }\end{array}$ & $\begin{array}{c}\text { Financial } \\
\text { Accounting } \\
\end{array}$ & $\begin{array}{l}\text { Managerial } \\
\text { Accounting } \\
\end{array}$ & $\begin{array}{l}\text { Weighted } \\
\text { Average }\end{array}$ \\
\hline 4 & $\begin{array}{l}\text { My learning increased as a result of using the computer-graded case } \\
\text { templates. }\end{array}$ & 3.36 & 3.46 & 3.41 \\
\hline 5 & The computer-graded case templates were not helpful in studying for tests. & 2.86 & 2.65 & 2.76 \\
\hline 6 & My excel skills improved as a result of the computer-graded templates. & 3.80 & 3.51 & 3.66 \\
\hline 11 & Doing the computer-graded case templates helped me do better on exams & 3.03 & 3.13 & 3.08 \\
\hline 16 & $\begin{array}{l}\text { I often just typed in formulas until it was "correct" without paying attention } \\
\text { to what I was doing. }\end{array}$ & 2.86 & 2.79 & 2.83 \\
\hline 17 & Completing the computer-graded templates helped me do better on exams & 3.08 & 3.20 & 3.14 \\
\hline 18 & $\begin{array}{l}\text { The computer-graded templates did not prepare me for the equations and } \\
\text { reasoning needed on the exams }\end{array}$ & 2.96 & 2.98 & 2.97 \\
\hline 22 & $\begin{array}{l}\text { If the computer-graded template said the answer was wrong, I generally did } \\
\text { not try to find out why. }\end{array}$ & $1.78 * *$ & $1.85 * *$ & 1.82 \\
\hline 25 & $\begin{array}{l}\text { I believe that using computers is an effective way to learn about accounting } \\
\text { and business. }\end{array}$ & $4.18 * *$ & $4.17 * *$ & 4.17 \\
\hline
\end{tabular}

The lack of significant perceived learning from the use of computer-graded templates is interesting. Faculty impressions that student performance improved add to the paradox. One explanation is that sophomore students often associate learning with the acquisition of facts, rather than the conceptual knowledge addressed by the templates. It is also possible that students connect learning with ability to perform better on exams. Since the exams did not present questions in the same format as the templates, students may not always see the templates as helping. Regardless, future research is required to shed light on this result.

\section{Improved Student Satisfaction}

Based on the survey, students liked the computer-graded template assignments. Students agreed with question 2, "I felt the computer-graded feature of the template was very helpful" at the .05 level of significance for both courses. "I found the color scheme in the computer-graded cases to be helpful," question 3, was significant at the .10 level for financial accounting and .15 level for managerial. The incorporation of color made the complex templates less confusing. With respect to the feedback aspect of the templates, students agreed at the .10 level in both courses with question 13, "I like the fact that I can see when the equation is correct, but the numerical value is wrong." For the managerial class, students agreed with question 14, "I like the fact that I get points when the equation is correct but the numerical value is wrong" at the .15 level.

Although financial students have a mildly more favorable view of accounting (question 20) as well as enjoying the class more than they thought they would (question 23), managerial students disagreed slightly with both questions. None of these results were significant at the .15 level. The failure of student satisfaction with the templates to translate into a better view of accounting or the course may be related to workload and examination expectations in both courses. Students found the courses more time-consuming than other courses taken, reflected by the responses to question 19. Although not asked in the survey, instructors continually receive complaints that the problem and short essay exam format is too difficult. It is always a challenge to get students to move past the recall knowledge level of learning.

\section{TEMPLATE BENEFITS AND DISADVANTAGES}

The following benefits and disadvantages were identified through discussions with the nine different instructors who taught the financial or managerial accounting course and used the templates over a one-year period of time. 
TABLE 3

Student Satisfaction

\begin{tabular}{|c|c|c|c|c|}
\hline \multicolumn{2}{|r|}{ Student Questionnaire } & \multicolumn{3}{|c|}{ Results } \\
\hline \# & $\begin{array}{l}\text { = Strongly Agree, } 4=\text { Agree }, 3=\text { Neutral, } 2=\text { Disagree, } \\
1=\text { Strongly Disagree }\end{array}$ & $\begin{array}{c}\text { Financial } \\
\text { Accounting }\end{array}$ & $\begin{array}{l}\text { Managerial } \\
\text { Accounting }\end{array}$ & $\begin{array}{l}\text { Weighted } \\
\text { Average }\end{array}$ \\
\hline 2 & I felt the instant grading feature of the template was very helpful. & $4.39 * * *$ & $4.43 * * *$ & 4.41 \\
\hline 3 & I found the color scheme for the computer-graded templates to be helpful. & $4.06^{* *}$ & $4.05^{*}$ & 4.06 \\
\hline 7 & $\begin{array}{l}\text { I found the computer-graded feature of the template to be frustrating at } \\
\text { times. }\end{array}$ & 3.25 & 3.01 & 3.14 \\
\hline 8 & I prefer doing the homework on templates I create myself. & 2.24 & 1.91 & 2.08 \\
\hline 10 & I think the computer-graded templates made the homework more fun. & 3.43 & 3.28 & 3.36 \\
\hline 13 & $\begin{array}{l}\text { I like the fact that I can see when the equation is correct but the numerical } \\
\text { value is wrong. }\end{array}$ & $4.03 * *$ & $4.14 * *$ & 4.08 \\
\hline 14 & $\begin{array}{l}\text { I like the fact that I get points when the equation is correct but the } \\
\text { numerical value is wrong. }\end{array}$ & 3.85 & $4.03 *$ & 3.94 \\
\hline 15 & I think the computer-graded templates should be required for this class. & 3.50 & 3.62 & 3.56 \\
\hline 19 & Compared to other courses, I spent less time on this course than others. & 2.00 & 1.88 & 1.94 \\
\hline 20 & I have a more favorable view of accounting after taking this class. & 3.22 & 2.83 & 3.03 \\
\hline 23 & I enjoyed this class more than I thought I would. & 3.21 & 2.87 & 3.04 \\
\hline & *** Significant at the .05 level; $* *$ Significant at the .10 level; * Significa & the .15 le & & \\
\hline
\end{tabular}

\section{Benefits For Students}

The benefits of the computer-graded templates to the students are numerous. Students receive immediate feedback and identify their errors more rapidly. For this reason, false concepts are not reinforced. Templates save time by providing an Excel format to solve the problem allowing students to spend their limited time on more sophisticated case requirements. The knowledge that the answer is correct instills confidence and alleviates the frustration students often feel. This in turn causes students to spend more time on task, motivated by the positive reinforcement of the "correct" grade. Each case template generally requires about an hour or more to complete. If the student's response to a case requirement is graded as "incorrect," the student can still advance to future requirements knowing that the "incorrect" on the previous answer will not affect the grade on future requirements. This knowledge encourages the student to complete the entire case instead of quitting prematurely.

The Excel skills of students improve dramatically as a result of the self-grading templates. Because many of the templates involve "what if" analysis, students learn early on the importance of entering formulas instead of numerical values whenever possible. The grading policy reinforces this notion by giving points for correct formulas, even when the numerical result is incorrect.

\section{Benefits For Faculty}

The computer-graded templates provide numerous benefits to the faculty as well. Because students feel more confident with their homework, they have fewer questions in class and during office hours. Traditionally, an average class period may have included 20-30 minutes of correcting homework. The computer-graded templates allow us to cut that time drastically. The in-class hours can now focus more on the decision use of the numerical information rather than its calculation. Students seem to enjoy the in-class discussions and are more willing to participate because they feel they understand the material. On certain days, we also added in-class group assignments and quizzes to reinforce the information covered in the template, giving the student yet another chance to absorb the material. Because the group assignments provide an opportunity to earn additional points, there has been an improvement in the overall attendance.

Comment boxes in the computer-graded templates allow the instructor to provide explicit instructions when needed. Each instructor can add any comments they want depending on the learning capabilities of the students. By changing the assumptions in the green areas of the template, faculty members can show students the impact of 
sensitivity analyses and "what if" assumptions. Faculty can easily show how different numerical scenarios provide support for particular business decisions.

Because the programming of templates automatically grades the student work, faculty spend less time grading homework. Grading for the numerical portion of the template is already summarized allowing the instructor to focus on the student's essay responses. The instructor can also demand a higher level of accuracy, because of the feedback provided by the templates.

The graduate teaching associates and part-time instructors felt the computer-graded templates provided better support for their classes because students are better able to learn on their own. The teaching associates also showed improved student assessments on the course surveys we administered, as well as on the student evaluation of teaching reports. One student reflected this in the following statement "The instructor wasn't as important when we got to the computer-graded cases because the case templates really helped us learn the material." For courses like introductory accounting with a large number of sections and high instructor turnover, computer-graded templates can provide critical instructor support while creating a more consistent approach across sections.

\section{Disadvantages For Students}

The biggest disadvantage for students is that a reasonable knowledge of Excel is required to use the templates. Although proficiency in Excel has improved dramatically in the last few years, generally about $15 \%$ of the students have little or no background in Excel. Our business program strongly encourages spreadsheet competency so student organizations generally offer Excel mini-courses for a fee at the beginning of the semester. Additionally students can learn Excel at the Student Computing Center.

Students report that the computer-graded feature is a very positive thing when the formula is "correct" but can be frustrating when they can't get the correct answer. Some students have remarked that occasionally they just "plug" formulas in until they get the answer correct without really understanding what they are doing. Most likely, these students would not have been aware of their incorrect answers until a much later date under traditional homework preparation methods. At least if the student is "plugging" that means the student immediately recognizes the original answer was in error. The introduction of in-class quizzes on the template material has encouraged students to spend more time analyzing what they are doing rather than just plugging in numbers on the template.

\section{Disadvantages For Faculty}

The primary disadvantage of the computer-graded templates is the time required to create a template. The faculty member must be able to create V Lookup tables, nested "IF" statements and understand conditional formatting in addition to basic Excel skills. Once the templates are prepared, however, revisions should be minimal. Traditional templates find their way into fraternity and sorority homework libraries. Because our templates provide each student with unique data, sharing homework solutions with other students has very limited benefit. Still, we suggest that instructors prepare several new templates each semester, thereby building up a template library over time.

\section{SUMMARY}

Computer-graded templates support the case-based, active learning pedagogy used in the introductory accounting courses, although the templates could be used in any course with a quantitative component. The benefits to both students and faculty easily outweigh the disadvantages. The templates provide critical instructor support by creating a more consistent approach across sections and reducing grading time. Questionnaire results show that students like the color scheme and the instant feedback of the excel-based templates and spend more time on task trying to find the "correct" answer. They also like the fact that they receive points when the formula was correct even if the ultimate numerical result was not. Although the students' view of the templates was positive, the template approach did not translate into a significantly better view of the course or accounting in general. 


\section{REFERENCES}

1. Chickering, A. W. \& Ehrmann, S. C. 1996. Implementing the Seven Principles: Technology as a Lever. AAHE Bulletin (October), 3-6.

2. Chickering, A. W. \& Gamson, Z. F. 1987. Seven Principles for Good Practice in Undergraduate Education, AAHE Bulletin (March), 5-13.

3. Kolb, D. A. 1984. Experiential learning: Experience as the Source of Learning and Development. (Englewood Cliffs, NJ: Prentice-Hall).

4. Glenberg, A. M., Bradley, M. M., \& Epstein, W. 1984. Co-activation and Comprehension: Contribution of Text Variable to the Illusion of Knowing. Memory and Cognition (Vol. 12) 355-360.

5. Homa, D. \& Cultice, J. 1984. Role of Feedback, Category Size, and Stimulus Distortion on the Acquisition and Utilization of Ill-defined Categories. Journal of Experimental Psychology: Learning, Memory \& Cognition (Vol. 10) 83-94.

6. Stuart, I. 2004. The Impact of immediate feedback on student performance: An exploratory study in Singapore: Global Perspectives in Accounting Education (Vol. 1) 1-15.

\section{NOTES}


NOTES 